\title{
PERHITUNGAN BOBOT RESIKO KREDIT DENGAN PENDEKATAN ADVANCED INTERNAL RATING BASED (AIRB) MODEL LGD
}

\author{
Nur Arina Hidayati \\ Program Studi Pendidikan Matematika FKIP UAD \\ Jl. Prof. Dr. Soepomo, SH. Janturan Yogyakarta. \\ E-mail: nurarinahidayati@gmail.com
}

\begin{abstract}
ABSTRAK
Tujuan dari penelitian ini adalah untuk membentuk model Loss Given Default (LGD) dengan distribusi beta dalam pendekatan Advanced-IRB (AIRB) dan mengaplikasikannya perhitungan menentukan bobot modal minimum.

Penelitian ini merupakan penelitian jenis studi literatur. Peneliti mengumpulkan beberapa konsep dari beberapa sumber misalnya buku, jurnal dan hasil penelitian yang relevan. Selanjutnya diambil studi kasus untuk mengaplikasikan model yang dikembangkan.

Perhitungan beban modal minimum (minimum capital charges) dengan pendekatan AIRB model LGD merupakan salah satu cara untuk menghitung bobot risiko kredit sebagai bagian dari upaya bank dalam manajamen risiko yang terjadi akibat debitur yang mengalami default.

Dengan pendekatan AIRB diperlukan komponen-komponen risiko yang diperlukan untuk perhitungan beban modal minimum ini, yaitu : Probability of Default (PD), Loss Given Default (LGD), Maturity (M). Selain itu, dalam model ini diperlukan juga komponen-komponen risiko yang lain, yaitu : Conditional Probability of Default (CPD), Conditional Loss Given Default (CLGD) dan Maturity Adjusment (MatAd).
\end{abstract}

Kata kunci : bobot modal minimum, LGD, CLGD

\begin{abstract}
The Calculation of minimum capital charges with LGD model of AIRB approach is one of ways to calculate the credit risk weight, a part of bank's efforts in managing the risks occurred because of defaulted debtors.

In the AIRB approach, it is required components risks required to calculate the minimum capital charges, namely Probability of Default (PD), Loss Given Default (LGD), Maturity (M). In addition, this model is also needed other risk components, namely: Conditional Probability of Default (CPD), Conditional Loss Given Default (CLGD) and Maturity Adjustment (MatAd). CLGD is a form of LGD modeling where the CLGD formulation formed by using beta distribution.
\end{abstract}

Key words: weight minimum capital, $P D, C P D, L G D, C L G D$ 


\section{Pendahuluan}

Bank merupakan suatu perusahaan yang menjalankan fungsi perantara (intermediasi) atas dana yang diterima dari nasabah, artinya bank adalah suatu lembaga yang menyalurkan dana deposito dari nasabah kepada perusahaan-perusahaan yang berupa suatu pinjaman. Salah satu kewajiban bank adalah menyediakan sejumlah dana yang siap digunakan atau ditarik kembali oleh nasabah ketika sewaktu-waktu nasabah membutuhkannya. Namun ada kalanya, karena buruknya kinerja bank dalam mengelola dana nasabah, bank tidak bisa memenuhi permintan nasabah yang berhak penuh atas dana yang disimpan di bank tersebut karena tidak tersedianya dana yang cukup untuk memenuhi permintaan nasabah. Atau dengan kata lain bank tidak memiliki dana kas yang cukup untuk membayar kembali nasabah yang ingin menarik dananya.

Karena pentingnya bank dalam melaksanakan fungsinya maka diperlukan suatu regulasi untuk mengatur kegiatan operasional bank. Hal ini bertujuan untuk menjaga kepercayaan nasabah terhadap aktivitas perbankan. Salah satu aturan yang perlu dibuat untuk mengatur perbankan adalah mengenai permodalan bank yang

Perhitungan... (Nur Arina Hidayati) berfungsi sebagai penyangga terhadap kemungkinan terjadinya kerugian.

Untuk menjalankan fungsi financial intermediary bank harus tetap hidup dan tumbuh, bahkan dalam kondisi yang tidak menguntungkan sekalipun. Dalam upaya untuk meningkatkan profit, salah satu faktor yang penting adalah meminimalkan risiko yaitu dengan cara mengelola risiko tersebut. Tujuannya adalah agar aktifitas operasional bank tidak menimbulkan kerugian yang melebihi kemampuan bank untuk menyerap kerugian, atau membahayakan kelangsungan usaha bank sehingga kemampuan perusahaan untuk menerima risiko tersebut sesuai dengan strategi yang ditetapkan.

Permodalan dalam dunia perbankan menjadi hal yang penting dilakukan karena fungsinya untuk menyangga bila terjadi risiko kredit. Bank harus melakukan perhitungan bobot modal (capital charges) sehingga apabila terjadi kredit macet, bank tersebut bisa tetap bertahan.

Dalam perhitungan risiko kredit, bank dapat memakai tiga pendekatan yang berbeda, yaitu Standardized Approach, Foundation Internal Rating Based (FIRB), dan Advanced Internal Rating Based (AIRB). Selain itu, Basel II juga mendefinisikan kriteria minimum yang harus dimiliki bank dengan menggunakan pendekatan IRB. 
Ada 4 komponen yang menjadi parameter utama dalam pendekatan IRB yaitu PD (Probability of Default), LGD (Lost Given Default), EAD (Exposure at Default) dan Maturity. Penelitian ini akan memaparkan tentang penerapan aturan Basel II dalam manajemen risiko kredit yang difokuskan pada perhitungan bobot penyisihan modal (capital charges) dengan pendekatan Advanced-IRB model LGD dengan distribusi beta .

Pendekatan Advanced-IRB model LGD dengan distibusi beta ini merupakan metode perhitungan modal yang dikembangkan dari aturan basel II, dimana LGD sebagai salah satu komponen dalam pendekatan Advanced$I R B$ ini akan diestimasi sehingga diperoleh suatu nilai yang menjadi bagian dalam perhitungan bobot penyisihan modal dengan menggunakan model distribusi beta.

\section{Metode Penelitian}

Penelitian ini merupakan penelitian jenis studi literatur. Peneliti mengumpulkan beberapa konsep dari beberapa sumber misalnya buku, jurnal dan hasil penelitian yang relevan. Selanjutnya diambil studi kasus untuk mengaplikasikan model yang dikembangkan.
Secara ringkas, dapat disusun diagram alur kerangka berfikir dalam penulisan karya ini, yaitu sebagai berikut:



Gambar 1. Skema alur berfikir

\section{Hasil dan Pembahasan}

\section{Asumsi-asumsi yang mendasari \\ Pendekatan AIRB}

Bobot risiko pada pendekatan AIRB ditentukan berdasarkan kerangka model Asymptotic Single Risk Faktor (ASRF). Dua Asumsi utama yang digunakan dalam model ini adalah 
a. Portofolio bank sangat granular

Maksudnya risiko idiosinkratik

terdiversifikasi secara sempurna karena

portofolio terdiri dari banyak eksposur

kecil. Idiosinkratik yaitu faktor yang secara spesifik berpengaruh kepada kepada masing-masing debitur.

b. Hanya terdapat satu faktor risiko sistematik yang mempengaruhi portofolio secara keseluruhan (Eva,2008).

Model ASRF berasal dari model portofolio kredit biasa dengan jumlah peminjam yang sangat besar. Risiko idiosinkratik yang berpengaruh pada tiap eksposur cenderung membatalkan risiko sitematik yang lain yang terdapat pada risiko tersebut (BCBS,2005).

\section{Komponen Risiko AIRB}

\section{Probability of Default (PD)}

Model unconditional probabilitas kegagalan (PD) ini menggunakan model Vasicek yang didasarkan pada model nilai aset Merton. Model ini juga mengasumsikan bahwa suatu perusahaan akan mengalami kerugian (default) jika nilai aset perusahaan $\left(A_{T}\right)$ lebih kecil dari nilai liabilitas $B$ yang dapat dibayarkan pada waktu T. Sehingga dapat ditentukan persamaan PD sebagai berikut:

$P D=P\left(A_{T}<B\right)$

Dalam hal ini, nilai total aset $A_{T}$ merupakan model geometric Brownian motion, yaitu sebagai berikut:

$d A_{t}=\mu A_{t} d t+\sigma A_{t} d W_{t}$

Dimana $\mu$ menunjukkan tingkat harga $d r i f t$, $\sigma$ menunjukkan volatilitas dan $W_{t}$ menunjukkan proses Wiener standar $W_{t}=\varepsilon \sqrt{d t}$, dimana $\varepsilon$ sampel random berdistribusi normal $\varepsilon \sim N(0,1)$.

Dengan aturan proses Itô dan Lemma Itô dapat ditentukan $d \ln A_{t}=d Y_{t}$.

$$
\begin{aligned}
d Y_{t} & =d \ln A_{t} \\
& =\left(\mu-\frac{1}{2} \sigma^{2}\right) d t+\sigma d W_{t} \\
\ln A_{t} & =\left(\mu-\frac{1}{2} \sigma^{2}\right) t+\sigma W_{t}
\end{aligned}
$$

Dari persamaan tersebut dapat ditunjukkan bahwa $\ln A_{t} \quad$ proses Wiener yang digeneralisasi dengan tingkat harga drift $\mu-\frac{1}{2} \sigma^{2}$ dan nilai variansinya $\sigma^{2}$. Dengan perubahan waktu $\ln A$ antara 0 sampai dengan $\mathrm{T}$.

Dapat dinyatakan, $\ln A_{t}=\ln A_{T}-\ln A_{0}$ $\ln A_{T}-\ln A_{0}=\left(\mu-\frac{1}{2} \sigma^{2}\right) \Delta t+\sigma \Delta W_{t}$

Sesuai dengan proses Wiener, $\Delta W_{t}=\varepsilon \sqrt{\Delta t}$, dimana $\varepsilon$ merupakan sampel random berdistribusi normal $\varepsilon \sim N(0,1)$. 
Sehingga,

$A_{T}=A_{0} \cdot \exp \left[\left(\mu-\frac{1}{2} \sigma^{2}\right) T+\sigma \varepsilon \sqrt{T}\right]$

Dengan menggunakan karakteristik proses Wiener $W_{t}=0$ dan berdasarkan persamaan (5) maka nilai Probability of Default (PD) pada persamaan (1) dapat ditentukan sebagai berikut:

$$
\begin{aligned}
P D & =P\left(A_{T}<B\right) \\
& =P\left(\ln A_{T}<\ln B\right) \\
& =P\left(\ln A_{0}+\left[\left(\mu-\frac{1}{2} \sigma^{2}\right) T+\sigma \varepsilon \sqrt{T}\right]<\ln B\right) \\
& =P\left(\varepsilon<\frac{-\left(\ln \frac{A_{0}}{\mathrm{~B}}+\left(\mu-\frac{1}{2} \sigma^{2}\right) T\right)}{\sigma \sqrt{T}}\right)
\end{aligned}
$$

Karena total aset mengikuti gerak Brown yang mengasumsikan bahwa sampel random berdistribusi normal dengan mean nol dan variansi $1 \quad N \sim(0,1)$, sehingga dapat ditetapkan probabilitas kegagalan dalam hubungannya dengan distribusi normal kumulatif, harga drift adalah harga risk free rate, sehingga $\mu$ dapat digantikan oleh. Sehingga persamaan (6) dapat dinyatakan sebagai :

$P=\Phi\left(\frac{-\left(\ln \frac{A_{0}}{\mathrm{~B}}+\left(\mu-\frac{1}{2} \sigma^{2}\right) T\right)}{\sigma \cdot \sqrt{T}}\right)$

\section{Conditional Probability of Default (CPD)} Merupakan komponen yang dikembangkan oleh Vasicek berdasarkan PD
Model Merton, atau sering disebut dengan Model Vasicek. Model Vasicek ini memperhitungkan nilai probabilitas dengan banyak peminjam. Dengan jumlah peminjam yang besar, akan memungkinkan portofolio pinjaman akan terbagi secara sempurna. Dalam hal ini, nilai dari aset-aset yang ada tidak berdiri sendiri-sendiri atau terpisah, faktor sistematik yang dimunculkan dalam model ini untuk menunjukkan bahwa nilai dari aset yang satu mempengaruhi terhadap nilai aset yang lain.

\section{Distribusi kerugian portofolio \\ Probability of Default model Vasicek} tidak harus dihitung dengan menggunakan model Merton (PD) tapi bisa digunakan parameter yang lain yaitu $\mathrm{PD}_{\mathrm{i}}$. $\mathrm{PD}_{\mathrm{i}}$ merupakan probabilitas default tak bersyarat (Unconditional Probability of Default) dari peminjam ke-i. Pada portfolio, diasumsikan suatu pinjaman akan mengalami default pada waktu $t=T$, jika nilai aset perusahaan $\left(A_{i}\right)$ lebih kecil dari nilai liabilitas/ kewajiban hutang $\left(B_{i}\right)$ yang dapat dibayarkan pada waktu $T$, dan tiap peminjam diasumsikan memiliki PD yang sama (Hibbeln, 2010). Sebagaimana dinyatakan dalam persamaan (1) yaitu:

$$
P D_{i}=P\left(A_{i T}<B_{i}\right)
$$


Setiap peminjam ke-i memiliki total aset $A_{i}$, dimana nilai total aset $A_{i}$ merupakan model geometric Brownian motion, sebagaimana dinyatakan dalam persamaan (2) yaitu sebagai berikut:

$$
d A_{i t}=\mu A_{i t} d t+\sigma A_{i t} d W_{t}
$$

$d W_{t}$ menggambarkan proses Wiener, dimana $\mathrm{n}=1,2,3, \ldots ., \mathrm{n}$. Nilai distribusi bersama aset pada waktu $\mathrm{T}$ dapat diwakili oleh :

$\ln A_{i T}=\ln A_{0}+\left(\mu_{i}-\frac{1}{2} \sigma_{i}^{2}\right) T+\sigma_{i} \varepsilon_{i} \sqrt{T}$

Presentase kerugian pada total portofolio (L) sama dengan jumlah peminjam yang default pada kewajiban hutangnya. Ketika faktor sistematik tetap, $\mathrm{D}_{\mathrm{i}}$ yang mengalami default sama dengan probabilitas default bersyarat (Conditional Probability of Default) pada Y, dan dinotasikan dengan $P D(\alpha)$, hal ini dapat ditunjukkan dengan uraian sebagai berikut:

$$
\begin{aligned}
P D(\alpha) & =P\left(D_{i}=1 \mid Y=\alpha\right) \\
& =P\left(A_{i T}<-B_{i} \mid Y=\alpha\right) \\
& =\Phi\left(\frac{\Phi^{-1}(P D)-\alpha \sqrt{\rho}}{\sqrt{1-\rho}}\right)
\end{aligned}
$$

Maka dapat ditentukan fungsi distribusi kumulatif dari portofolio kerugian, yaitu sebagai berikut:

$$
\begin{aligned}
& P(L \leq l)=P(P D(\alpha) \leq l) \\
& =P\left[\Phi\left(\frac{\Phi^{-1}(P D)-\alpha \sqrt{\rho}}{\sqrt{1-\rho}}\right) \leq l\right]
\end{aligned}
$$

$$
\begin{aligned}
& =P\left[\alpha<\frac{\Phi^{-1}(l) \sqrt{1-\rho}-\Phi^{-1}(P D)}{\sqrt{\rho}}\right] \\
& =\Phi\left[\frac{\Phi^{-1}(l) \sqrt{1-\rho}-\Phi^{-1}(P D)}{\sqrt{\rho}}\right]
\end{aligned}
$$

$\theta$ merupakan peluang (interval konfidensi) yang diinginkan oleh kreditur, menghitung persentil ke $-\theta$ sama dengan menghitung besarnya modal yang harus dialokasikan untuk portofolio kredit, sehingga dari perhitungan persentil ini dapat diketahui berapa modal yang dibutuhkan untuk menutup kerugian yang tidak diharapkan (UDR) (Vasicek, 2002).

Invers dari fungsi distribusi kumulatif kerugian portofolio ini merupakan persentil ke $-\theta$ dari L, disajikan persamaan sebagai berikut :

$$
\begin{aligned}
& \theta=\Phi\left[\frac{\Phi^{-1}(l) \sqrt{1-\rho}-\Phi^{-1}(P D)}{\sqrt{\rho}}\right] \\
& \Phi^{-1}(\theta)=\left[\frac{\Phi^{-1}(l) \sqrt{1-\rho}-\Phi^{-1}(P D)}{\sqrt{\rho}}\right] \\
& \Phi^{-1}(l)=\frac{\Phi^{-1}(\theta) \sqrt{\rho}+\Phi^{-1}(P D)}{\sqrt{1-\rho}} \\
& l=\Phi\left[\frac{\Phi^{-1}(\theta) \sqrt{\rho}+\Phi^{-1}(P D)}{\sqrt{1-\rho}}\right] \\
& L_{\theta}=F(\theta, 1-P D, 1-\rho) \\
& \quad=\left[\frac{\Phi^{-1}(\theta) \sqrt{\rho}+\Phi^{-1}(P D)}{\sqrt{1-\rho}}\right]
\end{aligned}
$$

$L_{\theta}$ ini dikatakan sebagai nilai kerugian yang tidak diharapkan (UDR), namun disebutkan juga dalam literatur yang lain bahwa 
ISSN: 2088-687X

$L_{\theta}$ adalah Conditional Probability of Default

(CPD) itu sendiri.

\section{Loss Given Default (LGD)}

LGD (Loss Given Default) adalah salah satu komponen dalam pendekatan Advanced IRB yang harus diestimasi untuk menentukan bobot penyisihan modal oleh bank. LGD adalah bagian kerugian bank yang tidak dapat kembali kepada bank akibat terjadinya default, setelah memperhitungkan agunan yang diberikan oleh debitur sebagai pengganti kewajiban debitur (Hibbeln, 2010).

Dalam penentuan nilai LGD, pada penelitian ini menggunakan model yang dikembangkan oleh Moody`s KMV, dengan formulasi untuk mengestimasi nilai adalah $\mathrm{LGD}=1$ - recovery rate. Recovery rate adalah bagian yang diterima bank apabila debitur default (Sugiarto, 2008). Pada penelitian ini bobot risiko yang dihitung adalah bobot risiko tanpa mitigasi. Pada formula Vasicek diasumsikan bahwa peminjam tidak menghasilkan pendapatan dan ketika peminjam mengalami kerugian (default) peminjam sudah tidak memiliki aset atau aset yang dimiliki kurang dari kewajiban hutang, sehingga tidak ada pemulihan atau recovery $=0$. Sehingga dapat diambil kesimpulan bahwa LGD bernilai 1 (Thomas, 2004).

\section{Conditional Loss Given Default (CLGD)}

Bobot risiko pada pendekatan AIRB ditentukan berdasarkan kerangka model Asymptotic Single Risk Faktor (ASRF), dimana dengan model ini diasumsikan tingkat kerugian portofolio yang terdiversifikasi dengan baik tergantung hanya pada faktor risiko sistematik tunggal dan tidak terkait faktor risiko idiosinkratik dengan satu exposur.

Variabel Y dapat diartikan sebagai faktor risiko sistematik dan L dinotasikan sebagai prosentase kerugian pada total portofolio, dinyatakan kerugian yang diperkirakan bersyarat (Conditional Expexted Loss) dengan $E[L \mid Y=\alpha]$, dimana $\alpha$ merupakan interval konfidensi 99,99\% dari distribusi normal standar atau dengan kata lain $\alpha$ sebesar $1 \%$.

Misalkan diambil variabel $\mathrm{D}$ yang akan bernilai 1 jika terjadi default dan 0 untuk yang lain, maka persamaan kerugian yang diperkirakan bersyarat dapat dinyatakan dengan persamaan berikut:

$$
\begin{aligned}
E[L \mid Y=\alpha]= & P\left(D_{i}=1 \mid Y=\alpha\right) \\
& \cdot E\left(D_{i}=1 \mid Y=\alpha\right)
\end{aligned}
$$

Selanjutnya, diasumsikan nilai return aset sebagai berikut:

$$
A_{i}=-Y \sqrt{\rho}+Z \sqrt{1-\rho}
$$


$A_{i}$ menyatakan aset return ke-i, variabel Y menyatakan faktor risiko sistematik yang merupakan variabel random berdistribusi normal, $\quad Y \sim N(0,1)$, sedangkan $Z_{i}$ dapat diartikan sebagai risiko idiosinkratik, diasumsikan independen terhadap variabel random dan $\sqrt{\rho}$ diartikan sebagai sebagai bobot risiko peminjam pada faktor risiko sistematik.

Jika kemampuan obligor untuk membayar hutang dari kerugian $\left(A_{i}\right)$ hanya mampu membayar hutang lebih sedikit dari beban yang harus ditanggungnya maka obligor dianggap tidak mampu membayar hutangnya. Ini dapat diartikan bahwa semakin kecil variabel $A_{i}$ maka semakin besar kerugian terjadi ketika obligor default. Dalam kasus ini, tingkat kerugian obligor (default) dapat diekspresikan sebagai suatu fungsi penurunan monoton atau fungsi monoton turun dari variabel $\left(A_{i}\right)$, yaitu:

$$
\begin{aligned}
L & =f\left(A_{i}\right) \\
& =f(-Y \sqrt{\rho}+Z \sqrt{1-\rho})
\end{aligned}
$$

Maka persamaan (1) dapat dinyatakan sebagai berikut:

$$
\begin{aligned}
& E[L \mid Y=\alpha]=P\left(D_{i}=1 \mid Y=\alpha\right) \\
& \quad \cdot E\left(D_{i}=1 \mid Y=\alpha\right) \\
& =P\left(A_{i} \leq B \mid X=\alpha\right) . E\left(f\left(A_{i}\right) \mid A_{i} \leq B, Y=\alpha\right) \\
& =C P D \times C L G D
\end{aligned}
$$

Dari persamaan (12) dapat ditentukan ekspektasi conditional LGD (CLGD), yaitu sebagai berikut:

$$
\begin{gathered}
C L G D=E\left(f\left(A_{i}\right) \mid A_{i} \leq B, Y=\alpha\right) \\
=E(f(-Y \sqrt{\rho}+Z \sqrt{1-\rho}) \mid-Y \sqrt{\rho}+Z \sqrt{1-\rho} \\
\leq B, Y=\alpha)
\end{gathered}
$$

Untuk mencari bentuk eksplisit dari ekspektasi CLGD ketika faktor risiko sistematik $Y$ dibentuk oleh $\alpha$, harus ditentukan probabilitas gabungan dari kerugian, default dan faktor risiko sistematik $P(L=l, D=1, Y=\alpha)$. Jadi probabilitas gabungan dapat diperoleh dengan mengubah pdf (probability distribution function) gabungan, dapat dinyatakan kembali dengan bentuk berikut ini:

$$
\begin{gathered}
P\left(-Y \sqrt{\rho}+Z \sqrt{1-\rho}=f^{-1}(t),-Y \sqrt{\rho}+Z \sqrt{1-\rho}\right. \\
\leq B, Y=\alpha)(17)
\end{gathered}
$$

Dan conditional pdf dari $P(L=l, D=$ $1, Y=\alpha$ ) secara eksplisit dapat dinyatakan sebagai berikut persamaan (18):

$$
\begin{aligned}
& P\left(A_{i}=f^{-1}(l) \mid A_{i} \leq\right.B, Y=\alpha) \\
&=\frac{\Phi\left(\frac{f^{-1}(t)+\sqrt{\rho} \alpha}{\sqrt{1-\rho}}\right)}{\Phi\left(\frac{C+\sqrt{\rho} \alpha}{\sqrt{1-\rho}}\right)} \cdot \frac{1}{\sqrt{1-\rho}} \\
&-\infty<f^{-1}(l) \leq B
\end{aligned}
$$

Dimana $\quad A_{i}=-Y \sqrt{\rho}+Z \sqrt{1-\rho}$ dan $B=$ $\Phi^{-1}(P D)$

Dari fungsi distribusi probabilitas bersyarat pada persamaan (7) dapat ditentukan nilai ekspektasinya, nilai ekspektasi ini adalah 
nilai dari CLGD. Sehingga nilai CLGD dapat diestimasi dengan persamaan berikut ini:

$$
\begin{aligned}
& E\left(f\left(A_{i}\right) \mid A_{i} \leq B, Y=\alpha\right)= \\
& \int_{-\infty}^{B} f(u) \frac{\phi\left(\frac{u+\sqrt{\rho} \alpha}{\sqrt{1-\rho}}\right)}{\Phi\left(\frac{A_{i}+\sqrt{\rho} \alpha}{\sqrt{1-\rho}}\right)} \cdot \frac{1}{\sqrt{1-\rho}} d u
\end{aligned}
$$

Dimana $f(u)$ merupakan fungsi distribusi beta $(0,1)$ dengan parameter $a \operatorname{dan} b$.

Diberikan fungsi densitas dari distribusi beta sebagai berikut:

$\beta(a, b ; u)=\frac{\Gamma(a+b)}{\Gamma(a) \Gamma(b)} u^{a-1}(1-u)^{b-1}, 0<u<1$

Kemudian parameter $a$ dan $b$ dapat dihitung dengan :

$$
a=\frac{L G D}{V L G D}(L G D(1-L G D)-V L G D)
$$

dan

$$
b=\frac{1-L G D}{V L G D}(L G D(1-L G D)-V L G D)
$$

Variansi LGD (VLGD) dapat dinyatakan sebagai persentase maksimal dari variansi $L G D(1-L G D)$ dari fungsi $f(u)$.

Sehingga persamaan (20) dan (21) dapat dinyatakan sebagai persamaan berikut:

$a=L G D \frac{1-v}{v}$

Dan

$b=(1-L G D) \frac{1-v}{v}$

Dalam model portofolio kredit, nilai $v$ ditentukan yaitu $v=0,25$ (Tasche,2010).

\section{Kesimpulan}

Dari komponen-komponen risiko pendekatan AIRB seperti yang dipaparkan sebelumnya, dapat ditentukan bobot risiko/rasio modal minimum yang dipersyaratkan untuk mengatasi risiko kredit (capital charges).

Besarnya bobot risiko kredit dapat ditentukan dengan persamaan berikut:

$$
\begin{array}{r}
\mathrm{C}=[C P D \times C L G D]-[P D \times L G D] \\
\times \frac{1+(\mathrm{M}-2.5) \mathrm{b}(\mathrm{PD})}{1-1,5 \mathrm{~b}(\mathrm{PD})}
\end{array}
$$

Penentuan rasio modal minimum merupakan syarat mutlak yang harus dilakukan oleh perusahaan perbankan. Para pelaku bisnis perbankan, disarankan untuk betul-betul memahami aplikasi atau penerapan dari aturan persyaratan modal ini. Memang tidak mudah mengaplikasikannya secara langsung karena berkaitan dengan rumus-rumus matematis yang tidak sederhana, sehingga model matematis ini dapat dikembangkan dalam software yang aplikatif sehingga mudah dioperasikan oleh pengguna khususnya pelaku bisnis perbankan.

\section{Daftar Pustaka}

Basel Committee on Banking Supervision, 2004, An Explanatory Note On the Basel II IRB Risk Weight Functions, Bank for International Settlements 
Press \& Communications CH-4002 Basel, Switzerland.

Hibbeln, M., 2010, Risk Management in Credit Portofolios. Concentration Risk and Basel II, Physica-Verlag. A Springer Company. Germany.

Kim, J., Kim, W. and Kim, K., 2007, Lost Given Default under the Asymptotic Single Risk Factor Assumption, AsiaPasific Journal of Financial Studies pp 223-236.

Kim, Myung-Jig, 2006, Downturn LGD, Best Estimate of Expected Loss, and Potential LGD under Basel II, Hanyang University, Korea.

Kulkani, A., et al., 2006, How Good is Merton Model at Assessing Credit Risk? Evidence from India. National Institude of Bank Management.
Lutkebohmert, E., 2008, Concentration Risk in Credit Portofolios, Springer, Germany.

Merton, R., C., 1974, On The Pricing of Corporate Debt : The Risk Stucture of Interst Rate, Journal of Finance, Vol.29, pages 449-470.

Vasicek, O., A., 1987, Probability of Loss on Loan Portfolio, KMV Corporation, California, USA.

Vasicek, O., A., 1991, Limiting Loas Loss Probability Distribution, KMV Corporation, California, USA.

Vasicek, O., A., 2002, The Ditribution of Loan Portfolio Value, Journal Published in Risk.

Witzany, J., 2009, Loss, Default, and Loss Given Default Modeling, Institute of Economic Studies, Faculty of Social Sciences, Charles University, Prague. 